\title{
Flora do Espírito Santo: Chrysophyllum (Sapotaceae)
}

\author{
Flora of Espírito Santo: Chrysophyllum (Sapotaceae)
}

\author{
Brenno Gardiman Sossai ${ }^{1,3} \&$ Anderson Alves-Araújo ${ }^{1,2}$
}

\begin{abstract}
Resumo
Chrysophyllum é o segundo maior gênero da família Sapotaceae com 71 espécies conhecidas e distribuídas em sua grande maioria nos Neotrópicos. No Brasil, estima-se a ocorrência de 31 espécies, das quais 14 são endêmicas. Estudos recentes apontaram a ocorrência de nove táxons para o Espírito Santo, no entanto, o reconhecimento e a distinção taxonômica dos mesmos é incipiente. Este estudo apresenta chave de identificação, ilustrações, comentários taxonômicos e informações a respeito dos estados de conservação e da distribuição geográfica de espécies de Chrysophyllum nativas do Espírito Santo. Um total de sete espécies ocorrentes em áreas de Floresta de Tabuleiro, de Altitude e de Restingas foram registradas: Chrysophyllum flexuosum, C. gonocarpum, C. januariense, C. lucentifolium, C. splendens, C. viride e Chrysophyllum sp. nov. Os caracteres mais importantes para a distinção das espécies foram: 1. Vegetativos: formato da folha, indumento foliar e a coloração e densidade do mesmo, a disposição das nervuras secundárias foliares e presença/ausência de lenticelas nos ramos; 2. Reprodutivos: tamanho da corola e indumento nos verticilos reprodutivos, formato e coloração dos frutos.
\end{abstract}

Palavras-chave: Ericales, Floresta Atlântica, Neotrópico, taxonomia.

\begin{abstract}
Chrysophyllum is the second largest genus in the Sapotaceae family with 71 known species, which are mostly distributed in the Neotropics. In Brazil, 31 species are recorded, out of them 14 are endemic. Recent manuscripts listed nine taxa as native from Espírito Santo state, however, taxonomic data and the real identity of them is incipient. Thus, herein key identification, illustrations, taxonomic comments, and information about the conservation status and geographical distribution of native Chrysophyllum from Espírito Santo state are provided. A total of seven species were recorded for areas of Tabuleiro Forest, Montane Forest, and Restingas: Chrysophyllum flexuosum, C. gonocarpum, C. januariense, C. lucentifolium, C. splendens, C. viride, and Chrysophyllum sp. nov. The most important characters for specific distinction are: 1 . Vegetative: leaf shape, foliar indumentum and coloring and density, secondary leaf vein arrangement, and presence/absence of lenticels on the branches; 2 . Reproductive: corolla size and indument in the reproductive verticils, shape and color of the fruits.
\end{abstract}

Key-words: Ericales, Atlantic Forest, Neotropics, taxonomy.

\section{Introdução}

Sapotaceae é constituída por 58 gêneros e cerca de 1.250 espécies distribuídas principalmente nas regiões subtropicais e tropicais do mundo (Pennington 1991; Pennington 2004;). A família ocorre preferencialmente em florestas úmidas de baixas altitudes, geralmente abaixo de $1.000 \mathrm{~m}$, e seu principal centro de diversidade é a América tropical
(Pennington 2004). No Brasil, são registrados 12 gêneros com cerca de 232 espécies, destas 49 são registradas para o Espírito Santo distribuídas em dez gêneros (BFG 2015).

Chrysophyllum L. (Chrysophylloideae) é o segundo maior gênero da família Sapotaceae, com 71 espécies conhecidas, distribuídas em sua grande maioria no Neotrópico (Pennington 1991).

\footnotetext{
${ }^{1}$ Universidade Federal do Espírito Santo - UFES/CEUNES, Prog. Pós-graduação em Biodiversidade Tropical - PPGBT, Rod. BR-101 Norte, Km 60, Litorâneo, 29934-900, São Mateus, ES, Brasil.

${ }^{2}$ Universidade Federal do Espírito Santo - UFES/CEUNES, Depto. Ciências Agrárias e Biológicas, Lab. Sistemática e Genética Vegetal, Rod. BR-101 Norte, Km 60, Litorâneo, 29934-900, São Mateus, ES, Brasil.

${ }^{3}$ Autor para correspondência: brenno.gs@gmail.com
} 
No Brasil, estima-se a ocorrência de 31 espécies, dentre as quais 14 são endêmicas. A grande maioria das espécies é registrada para a Floresta Amazônica (20 spp.), porém, outros biomas possuem ocorrência do gênero, a exemplo da Caatinga (duas spp.), Cerrado (cinco spp.) e Mata Atlântica (14 spp.). No Espírito Santo, são listadas nove espécies (BFG 2015, Dutra et al. 2015). O gênero Chrysophyllum pode ser distinto dos demais por apresentar folhas douradas ou ferrugíneas na face abaxial da lâmina foliar, estaminódios geralmente ausentes, quando presentes esses são vestigiais, venação terciária frequentemente paralela às secundárias e ausência de estípulas (Pennington 1991).

A Flora Neotrópica tornou-se um marco para a taxonomia de Sapotaceae (Pennington 1990), devido à disponibilização do tratamento taxonômico das 43 espécies de Chrysophyllum conhecidas até aquele momento. Estudos posteriores realizados em escala regional trouxeram atualizações para a taxonomia do gênero, por exemplo, Alves-Araújo \& Alves (2010), Fabris \& Peixoto (2013), Palazzo et al. (2010) e Pennington (1991). Para o Espírito Santo, apenas o trabalho realizado por Fabris \& Peixoto (2013) traz informações a respeito de Chrysophyllum, no entanto, só foram apresentados dados referentes às espécies nativas das restingas.

O presente trabalho visa ampliar o conhecimento taxonômico de Chrysophyllum para o Espírito Santo (ES). As espécies tiveram sua morfologia estudada, descrita e ilustrada, e os status de conservação atualizado. Adicionalmente, uma chave para identificação dos táxons foi elaborada.

\section{Material e Métodos}

Expedições a campo foram realizadas no período de fevereiro/2015 a julho/2016 para coleta do material botânico, o qual foi herborizado seguindo as técnicas propostas por Bridson \& Forman (1998). Amostras férteis foram armazenadas em solução alcóolica $70 \%$ para serem utilizadas na identificação e na confecção das descrições das espécies. Para cada coleta realizada, as coordenadas geográficas foram tomadas por meio do Sistema de Posicionamento Global (GPS). O depósito dos espécimes estudados coletados em campo foi realizado no Herbário da Universidade Federal do Espírito Santo (VIES), com duplicatas enviadas para a Coleção do Jardim Botânico do Rio de Janeiro (RB). A identificação dos táxons foi realizada com base em dados disponíveis na literatura (Pennington 1990; Alves-Araújo \& Alves 2010; Fabris \& Peixoto 2013) e confirmadas através de consultas às descrições originais.
A chave de identificação, as descrições e as ilustrações tiveram como base amostras analisadas provenientes preferencialmente do ES e depositadas nas coleções do CVRD, MBML e VIES (Thiers, continuamente atualizado). Além disso, imagens dos vouchers disponibilizadas em banco de dados on-line de espécimes adicionais e tipos nomenclaturais foram consultados nas coleções do CEPEC, ESA, F, G, K, M, MBM, NY, P, RB, UEC, UPCB (Thiers, continuamente atualizado). Quando necessário, materiais adicionais foram utilizados para complementação das descrições. $\mathrm{Na}$ ausência de materiais adicionais, as informações taxonômicas foram baseadas nas descrições realizadas por Pennington (1990). A descrição geral do gênero é baseada apenas amostras analisadas. A terminologia utilizada nas descrições morfológicas segue os conceitos de Hickey (1973) e Harris \& Harris (2001). Para a elaboração das ilustrações, foi utilizado estereomicroscópio acoplado à câmara clara. Apenas as espécies nativas do Espírito Santo foram incluídas neste estudo.

O estado de conservação global das espécies teve como base os critérios da IUCN (2017), sendo a Extensão de ocorrência (EOO) e Área de ocupação (AOO) calculadas com o Geospatial Conservation Assesment Tool (GeoCat) (Bachman et al. 2011). Os mapas de distribuição geográfica foram elaborados no software aplicativo Quantum-GIS 2.16.1.

Dados gerais referentes à vegetação podem ser encontrados em Garbin et al. (2017).

\section{Resultados e Discussão}

Sete espécies de Chrysophyllum foram registradas para o ES: Chrysophyllum flexuosum Mart., C. gonocarpum (Mart. \& Eichler ex Miq.) Engl., C. januariense Eichler, C. lucentifolium Cronquist, C. splendens Spreng., C. viride Mart. \& Eichler e Chrysophyllum sp. nov.

Táxons anteriormente listados como ocorrentes no estado (BFG 2015; Dutra et al. 2015) não são incluídos no presente trabalho de acordo com dois critérios: 1) Não terem sido encontrados durante as expedições de campo e/ou os materiais depositados nas coleções visitadas/consultadas não serem provenientes do ES, como constatado na base de dados disponíveis online (CRIA 2016). São exemplos, Chrysophyllum inornatum Mart. [Hatschbach, G. 79506 (MBM)], C. marginatum [(Hook. \& Arn.) Radlk. (Forzza, R.C. 1909 (RB)] e C. rufum Mart. [Freire, S.G. 11 (NY)]; e 2) Espécies exóticas, equívocos de determinação específica ou impossibilidade desta devido à ausência de caracteres 
vegetativos e reprodutivos necessários para este fim. São exemplos, Chrysophyllum prieurii A. de Candolle (L. Kollmann 2458 - MBML) que na realidade é uma amostra de Pouteria oblanceolata Pires; Chrysophyllum sanguinolentum subsp. spurium (Ducke) Pennington (BCTw 11993) que se trata de um fragmento de madeira, não sendo possível sua determinação; e Chrysophyllum cainito L. por se tratar de uma espécie exótica e cultivada e, por isso, não foi incluída nas análises taxonômicas deste trabalho.

Os caracteres vegetativos mais importantes para a distinção específica das espécies foram o formato da folha, o indumento foliar e a coloração e densidade do mesmo, a disposição das nervuras secundárias foliares e a presença/ausência de lenticelas no ramos. Além desses, caracteres como tamanho da corola, indumento presente nas partes reprodutivas e o formato e a coloração dos frutos, também foram úteis para a taxonomia do grupo.

Chrysophyllum gonocarpum apresenta ampla distribuição no Brasil e pode ser encontrada nos Domínios da Amazônia, Cerrado e da Mata Atlântica. Chrysophyllum flexuosum, C. januariense, C. lucentifolium, C. splendens, C. viride e Chrysophyllum sp. nov. possuem distribuição geográfica conhecida apenas para o território brasileiro, e todas são endêmicas da Mata Atlântica.

Chrysophyllum flexuosum, C. gonocarpum, C. januariense, C. lucentifolium, C. splendens e Chrysophyllum sp. nov. são frequentemente encontradas em Florestas de Tabuleiro e Florestas de Encostas. Chrysophyllum januariense e $C$. splendens foram registradas em restingas, e $C$. flexuosum, C. januariense, $C$. splendens e $C$. viride em Florestas de Altitude.

Quanto às categorias de ameaça, Chrysophyllum januariense é classificada Em Perigo (EN), C. lucentifolium como Vulnerável (VU) e C.flexuosum, C. gonocarpum, C. splendens e C. viride como Pouco Preocupante (LC). Chrysophyllum sp. nov. é considerada como Criticamente em Risco (CR). Apesar desta espécie ocorrer em uma área protegida, apenas uma população é conhecida até o presente momento.

\section{Chave de identificação das espécies de Chrysophyllum nativas do Espírito Santo}

1. Folhas alterno-espiraladas, glabras; fruto sulcados, 3-6-seminados.

2. Lenticelas ausentes; nervuras secundárias indistinguíveis das intersecundárias a olho nu

6. Chrysophyllum viride

2'. Lenticelas presentes; nervuras secundárias distinguíveis das intersecundárias a olho nu.

3. Ramos com tricomas ferrugíneos; pecíolos canaliculados; pedicelos 3-6 mm compr.; frutos globoides 2. Chrysophyllum gonocarpum

3'. Ramos com tricomas bege; pecíolos não canaliculados; pedicelos 1-2 mm compr.; frutos ovoides

4. Chrysophyllum lucentifolium

1'. Folhas alterno-dísticas, face foliar abaxial com indumento glabrescente, densamente pubescente, seríceo a viloso; frutos não sulcados, uniseminados.

4. Face foliar adaxial e abaxial glabrescente nas folhas maduras; corola com faces interna e externa com indumento pubescente ferrugíneo; anteras glabras; frutos globoides, sementes arredondadas 7. Chrysophyllum sp. nov.

4'. Face foliar abaxial densamente pubescente nas folhas maduras, serícea a vilosa; corola glabra; anteras pubescentes; frutos elipsoides a fusiformes.

5. Nervura central vilosa na face foliar abaxial; pedicelos velutinos; sépalas com face externa velutina 3. Chrysophyllum januariense

5'. Nervura central da face foliar abaxial serícea; pedicelo pubescente ou seríceo; sépalas com face externa pubescente.

6. Face foliar abaxial com indumento seríceo; sépalas 2-2,5 × 1,2-2,5 mm; corola 2,5-4 mm compr.; estilete 0,5-1 mm compr.; estigma 5-lobado ........ 5. Chrysophyllum splendens

6'. Face foliar abaxial com indumento densamente pubescente a seríceo; sépalas 3-3,5 $\times$ 2-2,5 mm; corola 4-5 mm compr.; estilete 2-2,5 mm compr.; estigma simples 1. Chrysophyllum flexuosum 
1. Chrysophyllum flexuosum Mart., Fl. bras. 20, Beibl. 2: 98.1837 (reprinted as Herb. Fl. bras. 98).

Figs. 1; 3a,b; 5j-q

Árvores de até $9 \mathrm{~m}$ alt. Ramos seríceos (quando jovens), pubescentes (quando maduros), tricomas dourados a bege, lenticelas presentes. Lâmina foliar 5,5-21,5 × 2,3-8,5 cm, alternodísticas, elípticas a oblongas, face adaxial indumento escasso, face abaxial densamente pubescente a seríceo, tricomas com coloração cobre, nervura central serícea, ápice acuminado a atenuado, base atenuada, venação broquidódroma a eucampto-broquidódroma, nervura secundária distinguível das intersecundárias a olho nu; pecíolo 0,5-1,4 cm compr. pubescente, tricomas dourados, canaliculado. Fascículos 2-7-flores. Flores pediceladas, pedicelo $0,5-1,8 \mathrm{~cm}$ compr., pubescentes com tricomas dourados a ferrugíneos. Sépalas 6, 3-3,5 × 2-2,5 mm, ovais, ápice obtuso a arredondado, face interna e externa pubescente com tricomas ferrugíneos. Corola 5-lobada, lacínios 1,5-2 × 2-2,5 mm, ovais, ápice obtuso, glabros, tubo $2,5-3 \mathrm{~mm}$ compr. glabro. Estames-5, filetes 1,8-2 mm compr. glabros, anteras $1,5-1,8 \mathrm{~mm}$ compr., pubescentes, bege. Ovário 5-locular, 1,8-2 mm compr., cônico, serício, ferrugíneo; estilete 2-2,5 $\mathrm{mm}$ compr., glabro; estigma simples. Frutos ca. $2,8 \times 1 \mathrm{~cm}$, elipsoides, não sulcados. Semente solitária, ca. 1,9 × 0,7 cm, com uma ampla cicatriz base-ventral.

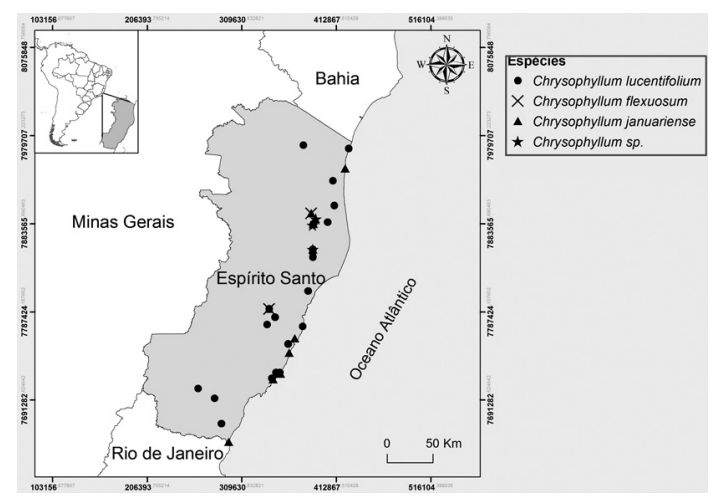

Figura 1 - Distribuição geográfica de Chrysophyllum flexuosum (X), Chrysophyllum januariense (triângulo), Chrysophyllum lucentifolium (círculo) e Chrysophyllum sp. nov. (estrela) no estado do Espírito Santo.

Figure 1 - Geographic distribution of Chrysophyllum flexuosum (X), Chrysophyllum januariense (triangle), Chrysophyllum lucentifolium (circle) and Chrysophyllum sp. nov. (star) in the state of Espírito Santo.
Material examinado: Águia Branca, Rochedo, Trilha do Córrego, 19.XII.2007, fl., V. Demuner et al. 4818 (MBML). Linhares, Rebio Sooretama, 16.XI.2015, B.G. Sossai et al. 69 (VIES). Santa Tereza, Estação Biológica de Santa Lúcia, 26.II.1991, fl., S.V. Pereira 64 (MBML). Material examinado adicional: BRASIL. RIO DE JANEIRO: Mangaratiba, Ilha da Marambaia, 10.VI.2006, fl., L.F.T. Menezes (VIES 22201).

É endêmica do Brasil e registrada para as regiões Nordeste (Bahia), Sudeste e Sul (Paraná) (Pennington 1990; BFG 2015). No ES, é registrada para Florestas Ombrófila Densa Montana, Floresta Estacional Semidecidual e Floresta de Tabuleiro. Dentre as espécies analisadas, pode ser reconhecida, principalmente, por suas folhas lanceoladas, ramos formando um zig-zag e frutos elipsoides. Floração observada em fevereiro, junho e novembro. Informações adicionais sobre os dados morfológicos dos frutos foram obtidos a partir das descrições disponibilizadas por Pennington (1990).

Estado de conservação: Pouco Preocupante (LC) (CNCFlora 2016).

2. Chrysophyllum gonocarpum (Mart. \& Eichler) Engler, Bot. Jahrb. Syst. 12: 523. 1890.

Figs. 2; 3c-e; 5r-b'

Árvores de até $21 \mathrm{~m}$ alt. Ramos pubescentes, tricomas ferrugíneos, lenticelas presentes. Lâmina foliar 5,5-16,5 × 2,5-4,5 cm, alterno-espiraladas, oblongas a elípticas, glabras, ápice cuneado a atenuado, base atenuada, venação eucamptódromabroquidódroma, nervuras secundárias distinguíveis

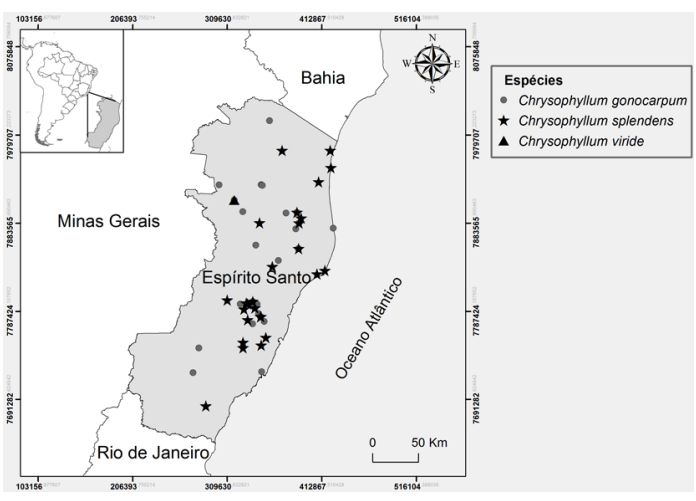

Figura 2 - Distribuição geográfica de Chrysophyllum gonocarpum (círculo), Chrysophyllum splendens (estrela) e Chrysophyllum viride (triângulo) no estado do Espírito Santo.

Figure 2-Geographic distribution of Chrysophyllum gonocarpum (circle), Chrysophyllum splendens (star) and Chrysophyllum viride (triangle) in the state of Espírito Santo. 

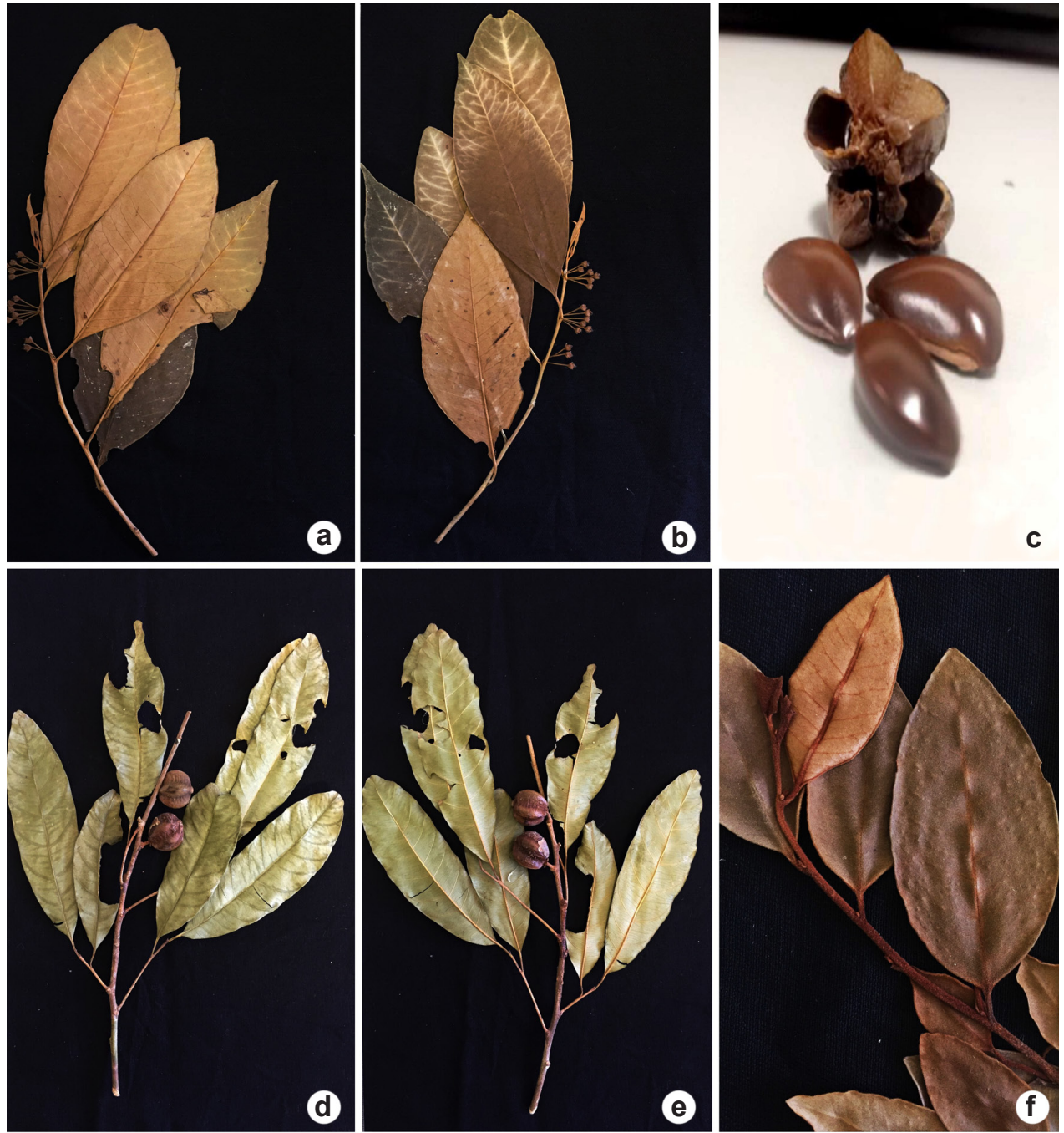

C
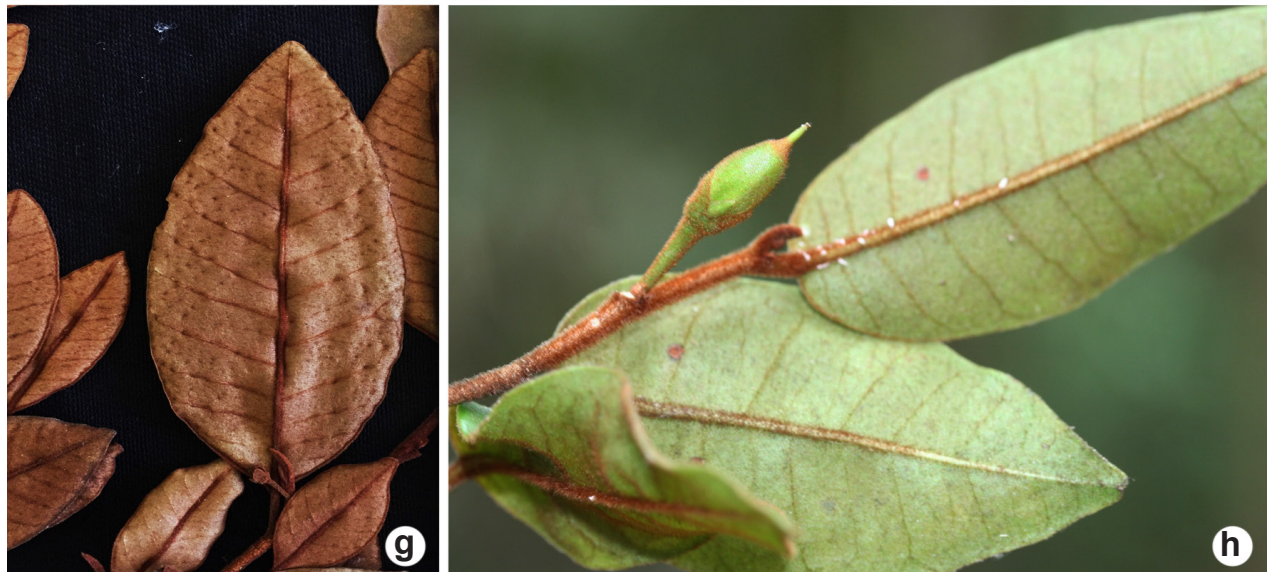

Figura 3 - a-b. Chrysophyllum flexuosum - a. ramo florífero em face abaxial; b. ramo florífero em face adaxial. c-e. Chrysophyllum gonocarpum - c. fruto e sementes; d. ramo frutífero em face adaxial; e. ramo frutífero em face abaxial. $\mathrm{f}-\mathrm{h}$. Chrysophyllum januariense - f. folha face adaxial; g. folha face abaxial; $\mathrm{h}$. fruto.

Figure 3 - a-b. Chrysophyllum flexuosum - a. flowering shoots in lower surface; b. floriferous shoots in upper surface. c-e. Chrysophyllum gonocarpum - c. fruit and seeds; d. fruitful shoots in upper surface; and. fruitful shoots on the lower surface. f-h. Chrysophyllum januariense -f. upper surface leaf; g. leaf lower surface; h. fruit. 
das intersecundárias a olho nu; pecíolo $0,8-1,8$ $\mathrm{cm}$ compr. pubescente a glabro, tricomas bege, canaliculado. Fascículos axilares e nas a ramifloras 6-28-flores. Flores pediceladas, pedicelo 3-6 mm compr. seríceo com tricomas dourados a ferrugíneos. Flores bissexuadas e unissexuadas. Sépalas 5, 2,5-3 × 1-2 mm, ovais, ápice obtuso a arredondado, face interna glabra, face externa serícea com tricomas ferrugíneos a dourados. Corola 5-lobada, lacínios 1,5-3 $\times$ 1-1,5 mm, ovais, ápice obtuso a agudo, glabro, tubo da corola 1-1,5 mm compr., glabro. Estames-5, filetes 1-2 mm compr. glabros, anteras $0,8-1,2 \mathrm{~mm}$ compr., glabras. Ovário 5-locular, 1-2 mm compr., ovoide, globoide a coniforme seríceo com tricomas dourados a ferrugíneos, estilete $0,5-1 \mathrm{~mm}$ compr. glabro; estigma simples. Frutos 2,2-3 cm, globoides, sulcados, amarelos a marrons (quando maduros), lustrosos quando secos. Semente 3-6, 1,8-2 cm, lustrosa, marrom, comprimida lateralmente, cicatriz 1,5-1,7 $\mathrm{cm}$ adaxial, estendendo-se a maior parte do comprimento da semente.

Material examinado selecionado: Castelo, Parque Mata das Flores, 15.VII.2015, fl., B.G. Sossai et al. 52 (VIES). Linhares, 10.X.1978, fl., I.A. Silva 24 (CVRD); 25.XI.2000, fl., D.A. Folli 3751 (CVRD); Reserva Vale, 12.XI.2004, fl., D.A. Folli 4967 (CVRD). Santa Leopoldina, Colina Verde, Morro do Agudo, 29.VIII.2007, fr., R.R. Vervloet 3336 (MBML). Sooretama, Rebio Sooretama, Estrada Estadual ES356, 16.XI.2015, B.G. Sossai 68 (VIES).

Espécie não endêmica do Brasil, amplamente distribuída na América do Sul (Argentina, Bolívia, Paraguai e Uruguai) e no território brasileiro nas regiões Norte (AC, PA e RO), Nordeste (BA, CE, MA, PE e RN), Centro-Oeste, Sudeste e Sul (Pennington 1990; BFG 2015). No ES, é registrada para Florestas Ombrófila Densa Montana, Floresta Estacional Semidecidual, Floresta de Tabuleiro e Restinga. Dentre as espécies analisadas, pode ser reconhecida, principalmente, por suas folhas alterno-espiraladas oblongas a elípticas, com nervura secundária em ambas as faces foliares evidentes, coberta por indumento branco quando jovens, tornando-se glabras posteriormente, e frutos amarelos a marrons quando maduros. Floração e frutificação observadas janeiro a fevereiro a outubro/dezembro e fevereiro a outubro, respectivamente. Pode ser confundida com C. viride, diferenciando-se pela presença de lenticelas e nervuras secundárias distinguíveis das intersecundárias a olho nu.
Nome poupular: Banha de Onça, Sapota Branca e Bapeba da Sombra (Espírito Santo), Bapeba (Bahia), Cutite Branco (Goiás), Guatambu (Paraná) e Aguaí da Serra (Santa Catarina).

Estado de conservação: Pouco Preocupante (LC), aqui proposto.

3. Chrysophyllum januariense Eichler, Vidensk. Meddel. Dansk Naturhist. Foren. Kjøbenhavn 1870: 206. 1870.

Figs. 1; 3f-h; 5a-i

Arbustos a árvores até $13 \mathrm{~m}$ alt. Ramos velutinos (quando jovens) com tricomas ferrugíneos, glabros a pubescentes (quando maduros) tricomas bege a ferrugíneos, lenticelas ausentes. Lâmina foliar 4,5-12 × 2-5 cm, alterno-dísticas, elípticas, lanceoladas a oblongas, face adaxial pubescente, tricomas ferrugíneos, face abaxial vilosa na nervura central e pubescente com tricomas ferrugíneos no restante da superfície, ápice atenuado, agudo a acuminado, base arredondada, atenuada, cuneada a truncada, venação broquidódroma, nervuras secundárias distinguíveis das intersecundárias a olho nu; pecíolo 4-8 mm compr. velutino ferrugíneo, não-canaliculado. Fascículos 2-6-flores. Flores pediceladas, pedicelo 3-8 $\mathrm{mm}$ compr., velutino com tricomas ferrugíneos a dourados. Sépalas $5,2-2,5 \times 1-2 \mathrm{~mm}$, ovais, ápice agudo a obtuso, face interna na região apical velutino, tricomas ferrugíneos (raramente glabras), face externa velutina a serícea com tricomas ferrugíneos a dourados. Corola 5-lobada, lacínios 1,5-2,5 × 1-2 $\mathrm{mm}$, ovais, ápice obtuso, glabro, tubo da corola $1,3-2 \mathrm{~mm}$ compr., glabros. Estames-5, filetes $1,2-1,3 \mathrm{~mm}$ compr. glabros, anteras $0,8-1,2 \mathrm{~mm}$ compr., pubescentes, bege. Ovário 5-locular, 1-3 $\mathrm{mm}$ compr., ovoide a cônico, seríceo, dourado; estilete 1-1,8 mm compr., glabro; estigma simples. Frutos 3-3,5 cm compr., marrons, elipsoides, não sulcados, velutinos, tricomas marrons. Semente solitária, 2-2,5 cm, lustrosa, não comprimida lateralmente, cicatriz $2-2,5 \mathrm{~cm}$, ocupando toda a face da semente.

Material examinado: Linhares, Reserva Biológica de Sooretama, 17.XI.2015, fl. e fr., B.G. Sossai et al. 73 (VIES); Reserva Natural Vale, 14.X.2015, B.G. Sossai et al. 65 (VIES); Reserva Natural Vale, 3.XI.1997, fr., M. Simonelli 672 (VIES). Santa Maria de Jetibá, Belém, 17.XII.2002, fl., L. Kollmann 5856 (MBML). Santa Teresa, Estação Biológica de Santa Lúcia, 3.XII.2014, fl., J. Freitas et al. 341 (VIES).

É endêmica do Brasil e registrada apenas para os estados da Bahia, Espírito Santo e Rio de Janeiro (Pennington 1990; BFG 2015). No ES, é registrada para Florestas Ombrófila Densa Montana, Floresta 
de Tabuleiro e Restinga. Dentre as espécies analisadas, pode ser reconhecida, principalmente, por suas folhas, jovens e/ou adultas, e face abaxial densamente velutina com tricomas ferrugíneos. Fruto verde quando imaturo e amarelo quando maduro. Floração e frutificação observadas de fevereiro a março/setembro a dezembro e maio a junho/setembro a novembro, respectivamente. Estudos realizados por Palazzo et al. (2012), mostraram variação na morfologia dos frutos de algumas amostras provenientes do Rio de Janeiro (globoides e amarelos).

Nome popular: Bapeba-veludo.

Estado de Conservação: Anteriormente considerada como Vulnerável (VU) pelo Livro Vermelho da Flora do Brasil (2013) e Extinta (EX) pela IUCN (2017), respectivamente. De acordo com os critérios da IUCN (2016), Chrysophyllum januariense é classificada como Em Perigo (EN) (B2abii, $\mathrm{AOO}=64 \mathrm{~km}^{2}$.

4. Chrysophyllum lucentifolium Cronquist, Bull. Torrey Bot. Club 73: 304. 1946.

Figs. 1; 4a-c; 6a-j

Árvores de até $30 \mathrm{~m}$ alt. Ramos pubescentes, tricomas bege, lenticelas presentes. Lâmina foliar 5,7-17,5 × 2,5-8,5 cm alterno-espiraladas, obovadas a elípticas, glabras, ápice atenuado, base aguda a atenuada, venação broquidódroma, nervuras secundárias distinguíveis das intersecundárias a olho nu; pecíolo 0,8-1,7 cm compr. pubescente, tricomas dourados a ferrugíneos, não canaliculado. Fascículos axilares a ramifloras 3-11-flores. Flores pediceladas, pedicelo 1-2 mm compr., pubescente com tricomas dourados. Sépalas 5, 1,4-1,7 × 0,8-1 $\mathrm{mm}$, lanceoladas, ápice obtuso, face interna glabra, face externa pubescente com tricomas dourados. Corola 5-lobada, lacínios 1,5-1,7 × 1-1,5 mm, ovais, ápice obtuso a cuneado, glabros, tubo da corola $0,8-1 \mathrm{~mm}$ compr., glabro. Estames-5, filetes $0,8-1 \mathrm{~mm}$ compr. glabros, anteras $0,8-1$ mm compr., glabras. Ovário 5-locular, 1-1,2 mm compr., ovoide, seríceo, tricomas bege a dourado; estilete $0,8-1 \mathrm{~mm}$ compr., glabro; estigma simples. Frutos 1,3-1,7 cm compr., amarelos, ovoides, sulcados, glabros. Sementes 3-4, 0,4-1,3 cm, lustrosa, comprimida lateralmente, marrom claro, cicatriz $0,8-1 \mathrm{~cm}$, estendendo-se a maior parte do comprimento da semente, as vezes ao longo da base.

Material examinado: Cachoeiro de Itapemirim, RPPN Cafundó, 15.II.2009, J.M.L. Gomes 3222 (VIES). Guarapari, Parque Estadual Paulo César Vinha,
28.X.1999, fr., A.M. Assis et al. 746 (VIES); Parque Estadual Paulo César Vinha, 22.VI.1998, fl., A.M. Assis et al. 522 (VIES); Parque Estadual Paulo César Vinha, 30.VI.1998, bot., A.M. Assis et al. 528 (VIES); Parque Estadual Paulo César Vinha, 2.VII.1999, bot. e fl., A.M. Assis et al. 707 (VIES); Parque Estadual Paulo César Vinha, 14.XI.2008, fr., L.C. Fabris et al. 870 (VIES). Linhares, Reserva Vale, 19.VII.1979, fl., I.A. Silva 43 (CVRD); Reserva Vale, 14.X.2015, fr., B.G. Sossai et al. 63 (VIES); Fazenda Glória, Restinga, 17.XII.1996, fr., O.J. Pereira et al. 5908 (VIES); Reserva Natural Vale, 3.XI.1981, bot. e fl., D.A. Folli 313 (VIES). Presidente Kennedy, Marobá, Praia das Neves, 19.VIII.2009, J.M.L. et al. 3383 (VIES). Santa Leopoldina, Fazenda Caioaba, 25.X.2007, fr., V. Demuner 4419 (MBML). Santa Tereza, Várzea Alegre, 23.X.2000, fr., V. Demuner 1535 (MBML); Estação Biológica Santa Lúcia, 25.I.2000, fr., $V$. Demuner 590 (MBML).

É endêmica do Brasil e registrada para os estados da Bahia, Espírito Santo e Rio de Janeiro (Pennington 1990; BFG 2015). No ES, é registrada para Florestas Ombrófila Densa Montana, Floresta Estacional Semidecidual, Floresta de Tabuleiro e Restinga. Dentre as espécies analisadas, pode ser reconhecida, principalmente, por suas folhas alterno-espiraladas, por sua nervação reticulada, evidente em ambas as faces e frutos sulcados amarelos a marrons quando maduros. Floração e frutificação observadas de junho/novembro de novembro/janeiro, respectivamente.

Nome popular: Uacá.

Estado de conservação: Anteriormente considerada como Pouco Preocupante (LC) (IUCN 2017), a espécie é recategorizada como Vulnerável (VU) $\left(\mathrm{B} 2 \mathrm{abii}, \mathrm{AOO}=28 \mathrm{~km}^{2}\right)$.

5. Chrysophyllum splendens Sprengel, Syst, veg. 1: 666. $1825 . \quad$ Figs. 2; 4f-h.; 6m-w

Árvores de até $19 \mathrm{~m}$ alt. Ramos seríceos (quando jovens) a pubescentes (quando maduros), tricomas dourados, lenticelas presentes. Lâmina foliar 5-21,5 × 2,7-9,5 cm, alterno-dísticas, elípticas, ovais e lanceoladas, face adaxial pubescente, tricomas dourados, face abaxial seríceo, tricomas dourados, nervura central serícea, ápice obtuso a cuspidado, base obtusa, venação broquidódroma, nervuras secundárias distinguíveis das intersecundárias a olho nu; pecíolo 0,5-2 cm compr. seríceo, tricomas dourados, canaliculado. Fascículos 4-15-flores. Flores pediceladas, pedicelo $0,6-2 \mathrm{~cm}$ compr., seríceo com tricomas dourados. Sépalas 5, 2-2,5 $\times 1,2-2,5 \mathrm{~mm}$, ovais, ápice obtuso, face interna na região apical pubescente, tricomas dourados, face 

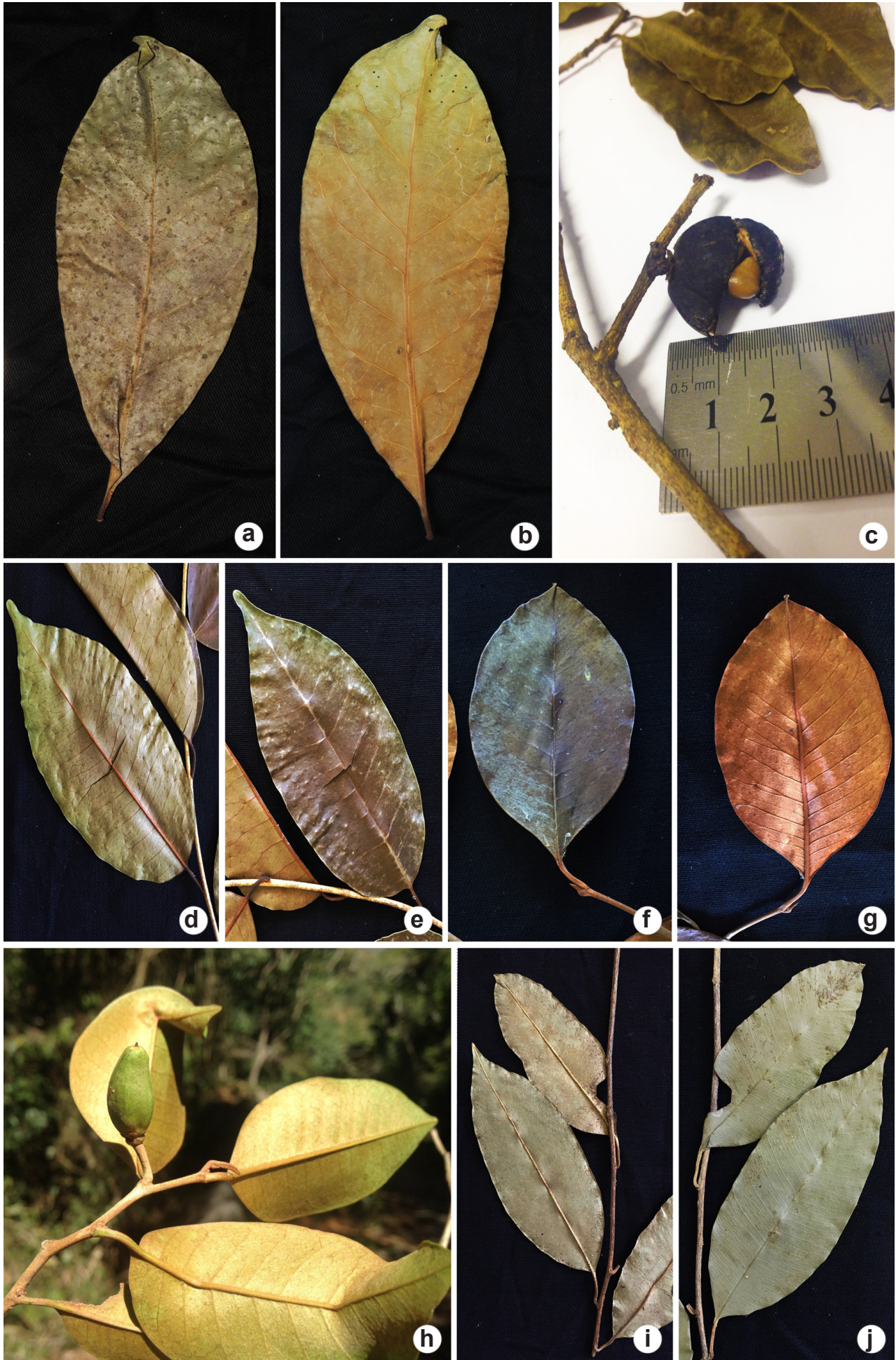

Figura 4 - a-c. Chrysophyllum lucentifolium - a. folha face adaxial; b. folha face abaxial; c. fruto. d,e. Chrysophyllum sp. nov. - d. folha face abaxial; e. folha face adaxial. f-h. Chrysophyllum splendens $-\mathrm{f}$. folha face adaxial; g. folha face abaxial; h. fruto. i-j. Chrysophyllum viride $-\mathrm{i}$. folha face abaxial; $j$. folha face adaxial.

Figure 4 - a-c. Chrysophyllum lucentifolium - a. upper surface leaf; b. leaf lower surface; c. fruit. d,e. Chrysophyllum sp. nov. - d. leaf lower surface; e. upper surface leaf. f-h. Chrysophyllum splendens $-\mathrm{f}$. upper surface leaf; $\mathrm{g}$. leaf lower surface; $\mathrm{h}$. fruit. i-j. Chrysophyllum viride $-\mathrm{i}$. leaf lower surface; $\mathrm{j}$. upper surface leaf. 


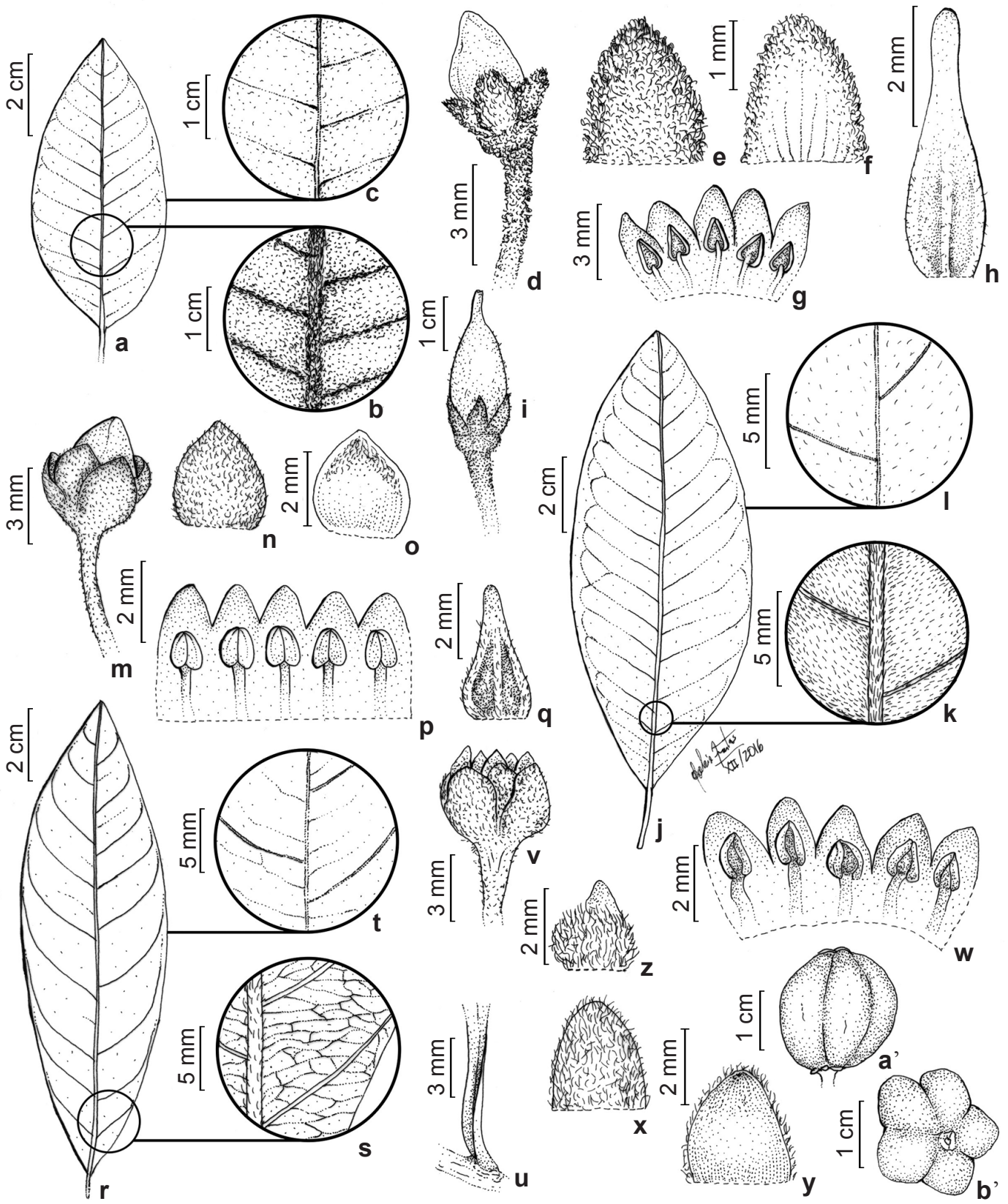

Figura 5-a-i. Chrysophyllum januariense - a. folha face abaxial; b. folha abaxial detalhe do indumento e nervura; c. folha adaxial detalhe do indumento e nervura; $d$. botão floral; e. sépalas face externa; f. sépalas face interna; g. corola e estames face interna; $h$. ovário e estilete; i. fruto. j-q. Chrysophyllum flexuosum - j. folha face abaxial; k. folha abaxial detalhe do indumento e venação; 1 . folha adaxial detalhe do indumento e venação; $m$. botão floral; $n$. sépala face externa; o. sépala face interna; $p$. corola e estames face interna; q. ovário e estilete. r-ac. Chrysophyllum gonocarpum - r. folha face abaxial; s. folha abaxial detalhe da venação; t. folha adaxial detalhe da venação; $u$. detalhe do pecíolo. v. flor; w. corola e estames face interna; x. sépalas face externa; y. sépalas face interna; z. ovário e estilete; a'. fruto em visão lateral; b' fruto em visão frontal.

Figure 5 - a-i. Chrysophyllum januariense - a. leaf lower surface; b. leaf lower surface detail of the indumentum and veins; c. upper surface leaf detail of the indumentum and veins; d. flower button; e. outer surface sepals; f. inner surface sepals ; g. corolla and stamens inner surface; $h$. ovary and stylet; i. fruit. j-q. Chrysophyllum flexuosum - j. leaf lower surface; k. lower surfasse leaf detail of the indumentum and venation; 1 . upper surface leaf detail of the indumentum and venation; $\mathrm{m}$. flower button; $\mathrm{n}$. outer surface sepals; $\mathrm{o}$. inner surface sepals; $\mathrm{p}$. corolla and stamens inner surface; $q$. ovary and stylet. $r$-ac. Chrysophyllum gonocarpum $-\mathrm{r}$. leaf lower surface; $\mathrm{s}$. leaf lower surface detail venation; t. upper surface leaf detail venation; u. detail of the petiole. v. flower; w. corolla and stamens innersurface; w. outer surface sepals; $y$. inner surface sepals; z. ovary and stylet; a'. fruit in side view; b' fruit in frontal view. 


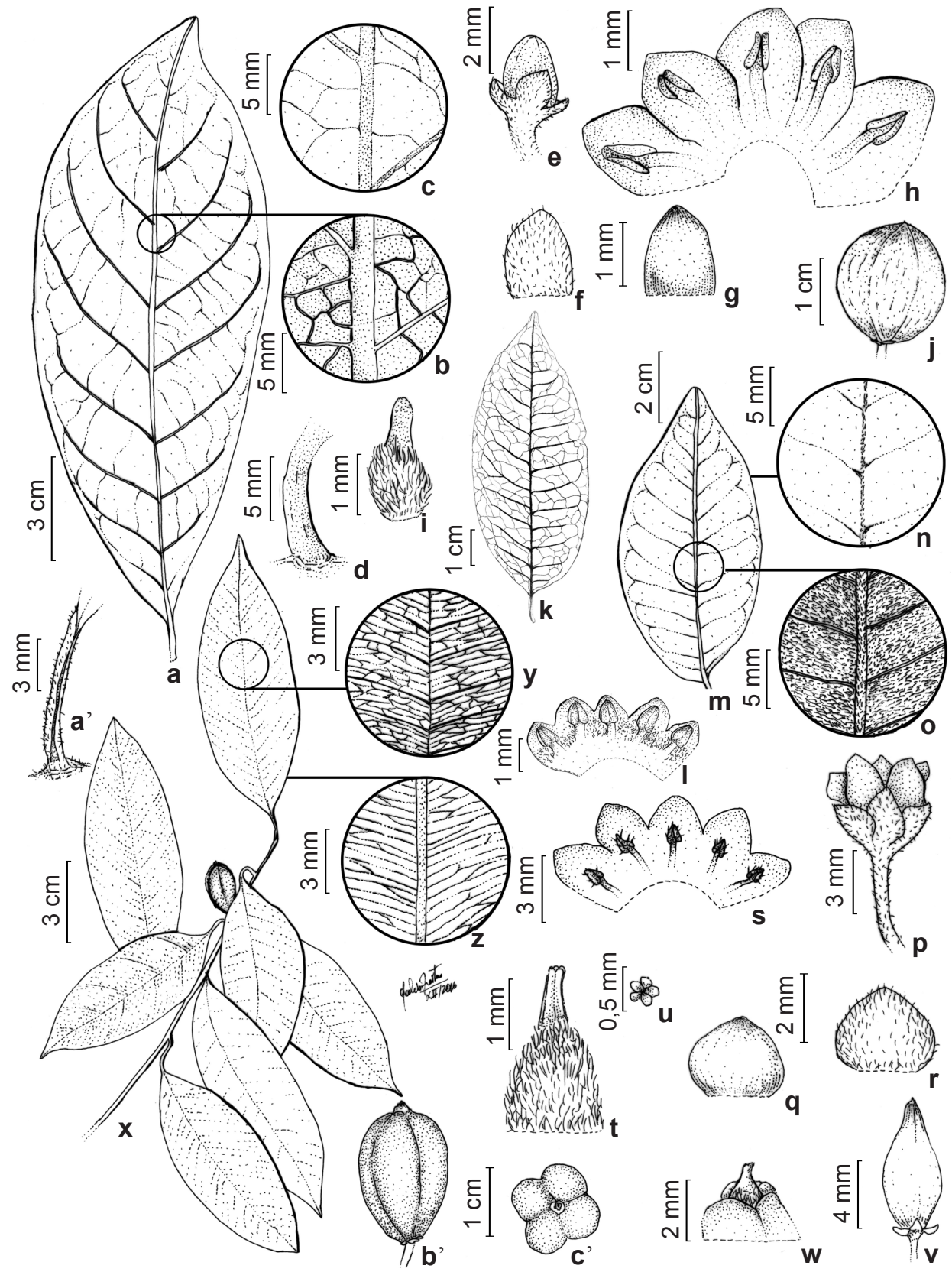

Figura 6-a-j. Chrysophyllum lucentifolium - a. folha face abaxial; b. folha abaxial detalhe da venação; c. folha adaxial detalhe da venação; d. pecíolo; e. botão floral; f. sépala face externa; g. sépala face interna; h. corola e estames face interna; i. ovário e estilete; j. fruto. k-1. Chrysophyllum sp. nov. - k. folha face abaxial; 1. corola e estames face interna. m-w. Chrysophyllum splendens $-\mathrm{m}$. folha face abaxial; $\mathrm{n}$. folha adaxial detalhe do indumento e nervuras; $\mathrm{o}$. folha abaxial detalhe do indumento e nervuras; p. flor; q. sépala face interna; r. sépala face externa; s. corola e estames face interna; t. ovário e estilete; u. detalhe do estigma; v. fruto; w. fruto detalhe do estigma persistente. $\mathrm{x}$-ad. Chrysophyllum viride - $\mathrm{x}$. ramo frutífero; $\mathrm{y}$. folha adaxial detalhe da nervação; z. folha abaxial detalhe da nervação; a'. pecíolo; b'. fruto visão lateral; c'. fruto visão frontal.

Figure 6-a-j. Chrysophyllum lucentifolium - a. leaf lower surface; b. leaf lower surface veins detail; c. upper surface leaf veins detail; d. petiole; e. flower button; f. outer surface sepals; g. inner surface sepals; h. corolla and stamens inner surface; i. ovary and stylet; j. fruit. k-l. Chrysophyllum sp. nov. - k. leaflower surface; 1 . corolla and stamens inner surface. m-w. Chrysophyllum splendens - $\mathrm{m}$. leaf lower surface; $\mathrm{n}$. upper surface leaf detail of the indumentum and veins; o. lower leaf detail of the indumentum and veins; $p$. flower; $q$. inner surface sepals; $r$. outer surface sepals; s. corolla and stamens inner surface; t. ovary and stylet; $\mathrm{u}$. detail of the stigma; $\mathrm{v}$. fruit; $\mathrm{w}$. fruit detail of persistent stigma. $\mathrm{x}$-ad. Chrysophyllum viride - $\mathrm{x}$. fruit shoots; $y$. upper surface leaf detail of the vein; z. leaf lower surface detail of the vein; a'. petiole; b' fruit in side view; c'. fruit frontal view. 
externa pubescente com tricomas dourados. Corola 5-lobada, lacínios 1,5-2,5 × 1-2 mm, ovais, ápice obtuso, glabros, tubo da corola 1-1,5 mm compr. glabro. Estames-5, filetes 0,5-1,3 mm compr. glabros, anteras 0,7-1 mm compr., pubescentes, bege. Ovário 5-locular, 1-2 mm compr., cônico, seríceo, dourado; estilete 0,5-1 mm compr., glabro; estigma 5-lobado. Frutos 2,5 × $1 \mathrm{~cm}$ compr., verdes (quando imaturos) a vermelhos (quando maduros), elipsoides a fusiformes, não sulcados, seríceos, tricomas dourados, estilete e estigma persistentes. Semente solitária, 1,2-2 ×0,7 cm, superfície lisa a levemente rugosa, não comprimida lateralmente, bege, cicatriz $7 \times 4 \mathrm{~mm}$ base-ventral.

Material examinado: Cariacica, Sítio Taquaruçu, 10.VI.2004, fr., F.Z. Saiter 76 (MBML). Conceição da Barra, Parque Estadual de Itaúnas, 23.XI.2015, fl., B.G. Sossai et al. 75 (VIES); área 135 da Aracruz Celulose S.A., 14.X.1992, bot., O.J. Pereira et al. 3925 (VIES). Domingos Martins, Sítio Rosa Freitas, as margens do Rio Jucu, 19.VII.2000, O.J. Pereira et al. 6286 (VIES). Linhares, 1.IV.1996, fr., D.A. Folli 2718 (CVRD); Reserva Florestal da Vale do Rio Doce, 8.II.1982, fl., I.A. Silva 314 (VIES); Reserva Florestal da Vale do Rio Doce, 17.II.1982, bot., I.A. Silva 318 (VIES). Santa Leopoldina, Suiça, 13.IV.2008, fr., M. Simonelli 1515 (MBML); Fazenda Caioaba, 5.I.2006, fl., L.F.S. Magnago 503 (MBML); Fazenda Caioaba, trilha do córrego Caioaba, 5.I.2006, fl., L.F.S. Magnago 446 (MBML); Serra do Ramalhete, Fazenda Caioaba, 14.II.2006, bot. e fl., V. Demuner 1793 (MBML). Santa Maria de Jetibá, Rio Nove, 24.II.2000, fl., V. Demuner 796 (MBML). Santa Tereza, Reserva Biológica Augusto Rusch, 30.IV.2002, fl., R.R. Vervloet 228 (MBML); Estação Biológica de Santa Lúcia, 3.VIII.1993, fr., L.D. Thomaz 873 (MBML); Estrada da Pedra da Onça, 30.XII.1998, fl., L. Kollmann 1438 (MBML); Estação Biológica Caixa D'água, 5.III.1999, bot. e fl., L. Kollmann 2028 (MBML); Estação Biológica Caixa D’água, 23.III.1999, fl., L. Kollmann 2225 (MBML); Estação Biológica Caixa D'água, 23.VI.1999, bot. e fr., L. Kollmann 2650 (MBML). Sooretama, Reserva Vale, Aceiro Baldo Faé, 12.VII.2016, fl., B.G. Sossai 93 (VIES).

É endêmica do Brasil e registrada para as regiões Nordeste (AL, BA, PE e SE) e Sudeste (ES, RJ) (Pennington 1990; BFG 2015). No ES, é registrada para Florestas Ombrófila Densa Montana, Floresta Ombrófila Submontana, Floresta Estacional Semidecidual, Floresta de Tabuleiro e Restinga. Dentre as espécies analisadas, pode ser reconhecida, principalmente, por suas folhas douradas na parte abaxial da lâmina, fruto verde quando imaturo e vermelho quando maduro, com formato elipsoide a fusiforme. Floração e frutificação observadas de fevereiro/ julho a setembro/dezembro e abril/setembro, respectivamente.

Nome popular: Bapeba-pedrim.

Estado de conservação: Considerada como Vulnerável (VU) pela IUCN (2017) e Quase Ameaçada (NT) pela CNCFLORA (2016). A espécie é aqui recategorizada como Pouco Preocupante (LC).

6. Chrysophyllum viride Martius \& Eichler in Miquel in Martius, Fl. bras. 7: 102. 1863.

Figs. 2; 4i-j; 6x-c'

Árvores de até $8 \mathrm{~m}$ alt. Ramos pubescentes, tricomas bege escassos, lenticelas ausentes. Lâmina foliar 6-16 × 1,6-5 cm alterno-espiraladas, oblongas a elípticas, glabras, ápice acuminado, base aguda cuneada, venação broquidódroma, nervuras secundárias indistinguíveis das intersecundárias a olho nu; pecíolo 1-2 cm compr. glabros, canaliculado. Fascículos axilares a ramifloras (2-)5-15-flores. Flores pediceladas, pedicelo 7-9 mm compr., indumento apresso esparso ou subglabros. Sépalas 5, 2-3 mm, ovais, ápice arredondado ou obtuso, face interna geralmente glabra, face externa pubescente. Pétalas 5-lobada, 3-3,5 mm, ovais, ápice obtuso, tubos igualando aos lóbulos, glabro. Estames 5, filetes ca. $2 \mathrm{~mm}$ compr. as vezes geniculado, glabros, anteras ca. 1 mm compr., ovais ou lanceoladas, glabras. Ovário 5-locular, curto e largo com indumento denso e longo, estilete 1-1,5 mm compr. glabro. Frutos 2,2$2,5 \times 1,3-1,5 \mathrm{~cm}$. Verde (quando imaturos) amarelo (quando maduros), globoides, sulcados, glabro. Semente 3-4, 1,6-1,8 × 0,4-0,6 cm, comprimida lateralmente, achatadas, lustrosa, marrom. Cicatriz 1,2-1,5 cm adaxial, estendendo-se a maior parte do comprimento da semente.

Material examinado: Águia Branca, 17.X.2006, fr., $V$. Demuner 2919 (MBML). Conceição do Castelo, Alto Bananal, 18.X.1985, fr., G. Hatschbach et al. 49925 (BR, MBM!, NY, UPCB!).

Material examinado adicional: BRASIL. PARANÁ: Guaraqueçaba, Rio do Cedro, 21.XI.1968, fl., G. Hatschbach 20347 (F). SÃO PAULO: Cunha, 12.XII.1996, fl., A.R. Ferretti et al. 22 (ESA).

É endêmica do Brasil e registrada para as regiões Nordeste (BA), Sudeste e Sul (Pennington 1990; BFG 2015). No ES, é registrada para Floresta Ombrófila Submontana. Dentre as espécies analisadas, pode ser reconhecida, principalmente, por seu tronco com casca áspera e acinzentada, suas folhas oblongas a elípticas alterno-espiraladas e frutos amarelos adocicados. 
Floração e frutificação observadas de outubro/ dezembro e maio/outubro. Informações adicionais sobre os dados morfológicos das flores foram obtidos a partir das descrições disponibilizadas em Pennington (1990). Pode ser facilmente confundida com Chrysophyllum gonocarpum (ver diferenças nos comentários da mesma).

Nome popular: Aguaí (Santa Catarina), Cacheta, Caixeta, caixeta amarela, caxeta, caxeta amarela (Paraná e Santa Catarina), Massaranduba (São Paulo).

Estado de conservação: Considerada como Quase Ameaçada (NT) pela IUCN (2017) e aqui recategorizada como Pouco preocupante (LC).

\section{Chrysophyllum sp. nov. Figs. 1; 4d,e; 6k-1}

Árvores de até $23 \mathrm{~m}$ alt. Ramos pubescentes (quando jovens), ferrugíneos, (quando maduros) indumento escasso a glabro, lenticelas presentes. Lâmina foliar 9-10 × 4-4,5 cm, alterno-dísticas, elípticas, face adaxial e abaxial com indumento glabrescente, tricomas ferrugíneos, nervura central nas folhas jovens pubescente, tricomas ferrugíneos, folhas maduras indumento escasso, ápice acuminado a atenuado, base obtusa a cuneada, venação broquidódroma, nervuras secundárias distinguíveis das intersecundárias a olho nu; pecíolo 0,8-1 cm compr. pubescente, canaliculado, pubescente, tricomas ferrugíneos. Fasciculos axilares a ramifloras 12-45-flores, creme. Flores pediceladas, pedicelo $1,8-3 \mathrm{~mm}$, compr., seríceo, tricomas ferrugíneo a dourados. Sépalas 5-6, 1-1,2 × 0,5-1 mm, ovais, ápice atenuado a agudo, face interna seríceo, tricomas dourados, face externa pubescente, tricomas ferrugíneos. Corola 5-6-lobada, lacíneos 1,2$1,5 \times 0,7-1 \mathrm{~mm}$, elíptica a lanceolada, ápice agudo a atenuado, face interna e externa com indumento pubescente ferrugíneo, tubo $0,3-0,5$ $\mathrm{mm}$ pubescente, tricomas ferrugíneos. Estames 5-6, filetes $0,4-0,7 \mathrm{~mm}$ compr. glabros, anteras 0,7-0,9 mm compr., glabras. Ovário 5-locular, 1 mm compr., ovoide a globoide, seríceo, ferrugíneo, estilete $0,5-1 \mathrm{~mm}$ compr. glabro; estigma simples. Frutos $0,8-1,2 \mathrm{~cm}$, verde a amarelado (quando imaturos) vermelho (quando maduros), globoides, não sulcados, rugosos, glabros. Semente solitária, 6-8 mm, lustrosa, não comprimida lateralmente, arredondada, marrom-claro, cicatriz 4-6 mm compr., oval irregular.

Material examinado: Linhares, Reserva Vale, 14.X.2015, B.G. Sossai et al. 64 (VIES); Reserva Natural Vale, 6.VII.2006, fl., D.A. Folli 5316 (CVRD); Reserva
Vale, 6.VI.1997, fl., D.A. Folli 3038 (CVRD, VIES). Sooretama, Reserva Vale, 2.IX,2014, fr., D.A. Folli 7248 (CVRD, HUEFS).

Chrysophyllum sp. nov. é uma nova espécie para a ciência e que se encontra em vias de publicação (Sossai \& Alves-Araújo, no prelo) e é conhecida apenas para o Espírito Santo ocorrendo em áreas de Floresta de Tabuleiro, na Reserva Natural Vale (Linhares).

Pode ser reconhecida, principalmente, por suas folhas elípticas com ápice acuminado a atenuado, e pelo fruto verde a amarelado quando imaturo e vermelho quando maduro. Além disso, é a única espécie que apresenta tricomas no interior da corola (tubo e lacínio). Floração e frutificação observadas de junho e julho e setembro respectivamente.

Estado de conservação: de acordo com a IUCN (2017) [B1, B2a, B2b (ii, iii)] e GeoCat (Bachman et al., 2011), como Criticamente em risco (CR). Até agora, Chrysophyllum sp. nov. exibe uma extensão de ocorrência (EOO) $(<100$ $\left.\mathrm{km}^{2}\right)$ e área de ocupação $(\mathrm{AOO})\left(<10 \mathrm{~km}^{2}\right)$. Apesar de ter ocorrido em uma determinada área protegida, apenas uma população é conhecida.

\section{Agradecimentos}

À CAPES, por ter concedido o auxílio financeiro através da concessão de bolsa de Mestrado ao primeiro autor; à equipe do Laboratório de Sistemática e Genética Vegetal (SGV) da UFES/ CEUNES, o apoio durante as coletas; ao CEUNES/ UFES, por toda a infraestrutura necessária para coletas e análises; aos curadores dos herbários CVRD, MBML e VIES, a disponibilização das amostras nas coleções; aos revisores que contribuíram para melhoria deste trabalho.

\section{Referências}

Alves-Araújo A \& Alves M (2010) Flora da Usina São José, Igarassu, Pernambuco: Sapotaceae. Rodriguésia 61: 303-318.

APG IV - The Angiosperm Phylogeny Group (2016) An update of the Angiosperm Phylogeny Group classification for the orders and families of flowering plants: APG IV. Botanical Journal of the Linnean Society 181: 1-20.

Bachman S, Moat J, Hill AW, de la Torre J \& Scott B (2011) Supporting red list threat assessments with GeoCAT: geospatial conservation assessment tool. In: Smith V \& Penev L (eds.) e-Infrastructures for data publishing in biodiversity science. ZooKeys 150: 117-126. (Version BETA)* 
BFG - The Brazil Flora Group (2015) Growing knowledge: an overview of seed plant diversity in Brazil. Rodriguésia 66: 1085-1113.

Bridson D \& Forman L (1998) The herbarium handbook. Royal Botanical Garden, Lubrecht \& Cramer, Richmond. 348p.

Corrales FM, Mantovani W \& Catharino ELM (1986) Estudos preliminares da biologia floral de Chrysophyllum auratum Miq. (Sapotaceae) em Piracicaba, estado de São Paulo. Anais da Escola Superior de Agricultura Luiz de Queiroz 43: $147-$ 157.

Couto HTZ, Tomazello Filho M, Chimelo JP \& Garcia PV (1983) Madeiras de espécies florestais do estado do Maranhão: I- identificação e aplicações. IPEF 23: $21-28$.

Dutra VF, Alves-Araújo A \& Carrijo TT (2015) Angiosperm checklist of Espírito Santo: using electronic tools to improve the knowledge of an Atlantic Forest biodiversity hotspot. Rodriguésia 66: 1145-1152.

Fabris LC \& Peixoto AL (2013) Sapotaceae das restingas do Espírito Santo, Brasil. Rodriguésia 64: 263-283.

Garbin ML, Saiter FZ, Carrijo TT \& Peixoto AL (2017) Breve histórico e classificação da vegetação capixaba. Rodriguésia 68: 1883-1894.

Gomes R, Pinheiro MCB, Lima HA \& SantiagoFernandes LDR (2010) Biologia floral de Manilkara subsericea e de Sideroxylon obtusifolium (Sapotaceae) em restinga. Revista Brasileira de Botânica 33: 271-283.

Gomes R \& Pinheiro MCB (2007) Biologia floral de Pouteria venosa (Martius) Baehni (Sapotaceae) na restinga de Maricá-RJ. Revista Brasileira de Biociências 5: 108-110.

Harris JG \& Harris MW (2001) Plant identification terminology: an illustrated glossary. $2^{\text {nd }}$ ed. Spring Lake Publishing, Spring Lake. 206p.

Hickey LJ (1973) Classification of the architecture of dicotyledonous leaves. American Journal of Botany 60: 17-33.

IUCN - International Union for Conservation of Nature (2017) Guidelines for using the IUCN red list categories and criteria. Version 13. Prepared by the Standards and Petitions Subcommittee. Disponível em <http://www.iucnredlist.org/
documents/RedListGuidelines.pdf>. Acesso em 16 fevereiro 2017.

Palazzo FM, Monteiro MHDA \& Andreata RHP (2012) Chrysophyllum januariense Eichl. (Sapotaceae): nova ocorrência para o Brasil e descrição do fruto. Pesquisas, série Botânica 63: 213-218

Palazzo FMA, Dias Neto AO, Monteiro MHDA \& Andreata RHP (2010) Sinopse comentada de Sapotaceae no município de Rio das Ostras (RJ, Brasil). Pesquisas, série Botânica 61: 293-306.

Pennington TD (2004) Sapotaceae (Sapodilla family). In: Smith N, Mori SA, Henderson A, Stevenson D Wm \& Heald SV (eds.) Flowering plants of the Neotropics. Princeton University Press, The New York Botanical Garden, New Jersey. Pp. 342-344.

Pennington TD (1990) Flora neotropica monograph 52. Sapotaceae. The New York Botanical Gardens, New York. Pp. 1-777.

Pennington TD (1991) The genera of Sapotaceae. The Royal Botanical Garden, Kew. 295p.

Ribeiro J (2008) Avaliação ambiental econômica da produção de madeira de espécie nativa em dois municípios na Amazônia brasileira. Dissertação de Mestrado. Universidade de São Paulo, São Paulo. $42 \mathrm{p}$.

Ribeiro JELS \& Pennington TD (1999) Sapotaceae. In: Ribeiro JELS, Hopkins MJG, Vicentini A, Sothers CA, Costa MAS, Brito JM, Souza MAD, Martins LHP, Lohmann LG, Assunção PACL, Pereira EC, Silva CF, Mesquita MR \& Procópio LC (eds.) Flora da Reserva Ducke: guia de identificação das plantas vasculares de uma floresta de terra-firme na Amazônia Central. INPA, Manaus. Pp. 312-331.

SpeciesLink (2016) Ferramenta desenvolvida pelo CRIA. Disponível em $<$ http://www.splink.org.br $>$. Acesso em 10 fevereiro 2017.

Thiers B [continuamente atualizado] Index herbariorum: a global directory of public herbaria and associated staff. New York Botanical Garden's Virtual Herbarium. Disponível em $<$ http://sweetgum.nybg. org/science/ih/>. Acesso em 16 fevereiro 2017.

Tropicos (2016) Missouri Botanical Garden. Disponível em <http://www.tropicos.org > . Acesso em 25 agosto 2016.

Watson G (1938) Nahuatl words in American english. American Speech 13: 113-114. 


\author{
Lista de exsicatas examinadas \\ 1- Chrysophyllum flexuosum Martius \\ 2- Chrysophyllum gonocarpum (Martius \& Eichler) Engler \\ 3- Chrysophyllum januariense Eichler \\ 4- Chrysophyllum lucentifolium Cronquist \\ 5- Chrysophyllum sp. nov. \\ 6- Chrysophyllum splendens Sprengel \\ 7- Chrysophyllum viride Martius \& Eichler in Miquel in Martius
}

Assis AM 522 (4), 528 (4), 531 (4), 628 (3), 707 (4), 746 (4), 1216 (6), 2388 (2). Costa MB 39 (2). Demuner V 590 (4), 796 (6), 836 (2), 1793 (6), 1956 (2), 2906 (2), 2919 (7), 4199 (2), 4306 (2), 4419 (4), 4642 (2), 4818 (1), 4946 (2). Dutra RLS 89 (2). Fabris LC 708 (3), 860 (3), 870 (4). Farias GL 195 (6). Freitas J 341. Folli DA 198 (3), 313 (4), 362 (6), 1435 (2), 2450 (4), 2718 (6), 3038 (5), 3751 (2), 4967 (2), 5064 (2), 5088 (4), 7248 (5), 7406 (5), 5316 (5). Glaziou A 11582 (1). Gomes JML 3158 (3), 3222 (4), 3383 (4), 3887 (4), 4020 (4). Hatschbach G 20357 (7), 49925 (7). Ivanauskas NM 544 (1). Jardim JG 107 (6). Kollmann L 751 (2), 1032 (2), 1150 (2), 1430 (2), 1438 (6), 1448 (2), 2028 (6), 2225 (6), 2259 (6), 2352 (2), 2650 (6), 3354 (2), 4391 (2), 5261 (6), 5856 (3). Labiak P 5059 (2). Leoni LS 5921 (4). Lucas E 828, 843 (4). Luz AA da 97 (4), 207 (2), 471 (2). Magnago LFS 446 (6), 503 (6), 1210 (2), 1505 (4), 1677 (2). Martins MLL 209 (4), 214 (4). Menezes LFT VIES 22201 (1). Milanezi MA VIES 793 (4). Pereira OJ 297 (4), 1358 (4), 2184 (2). 3925 (6), 4329 (6), 5545 (2), 5590 (4), 5746 (2), 5908 (4), 5922 (2), 6226 (3), 6286 (6), 6780 (4), 7171 (2), VIES 14950 (4). Pereira SV 64 (1). Rezende GSZ 51 (2). Saiter FZ 76 (6), 264 (2), 283 (3), 76 (6). Sanchez M 1807 (7). Silva IA 24 (2), 43 (4), 314 (6), 315 (6), 318 (6), 322 (6), 323 (6), 324 (6), 326 (6). Silva LA 403 (2). Simonelli M 1515 (6), 5775 (3). Siqueira GS 183 (2), 233 (5), 287 (6), 544 (3), 988 (5). Sobral M 3672 (2). Sossai BG 50 (6), 52 (2), 62 (6), 63 (4), 64 (5), 65 (3), 66 (2), 67 (6), 68 (2), 69 (1), 73 (3), 75 (6), 92 (6), 93 (6). Souza VD 382 (2), 418 (6). Spada J 25 (6), 152 (6). Thomaz LD 873 (6), MBML 9859 (6), 1547 (2). Vervloet RR 228 (6), 396 (2), 825 (2), 2860 (2), 2878 (2), 3336 (2). Vivas CV 03 (6). 